\title{
TRADICIÓN HEROICA Y EREMÍTICA EN EL ORIGEN DE ESPLANDIÁN
}

\author{
Paloma Gracia \\ Universidad de Alcalá de Henares
}

A Valentin

El nacimiento de Esplandián integra los motivos propios del arquetipo heroico como son abandono, amamantamiento por un animal salvaje, y crianza fuera del hogar a cargo de un individuo de condición inferior y en un lugar apartado ${ }^{1}$; al igual que el nacimiento de su padre, Amadís $^{2}$, y los de diver-

1 Véase para el nacimiento heroico el estudio clásico de Otto Rank, El mito del naci. miento del héroe, Barcelona, Paidós, 1981, y para una interpretación psicológica de sus circunstancias arquetípicas y del abandono en especial, C. G. Jung, «The Psycology of the Child Archetype» $\mathrm{y}$ «The Special Phenomenology of the Child Archetype», en Psyche and Symbol, ed. Violet S. de Laszlo, Nueva York, Anchor, 1958, págs. 113-147, que pueden leerse en versión francesa incorporados a Introduction d l'essence de la mythologie. L'enfant divin. La jeune fille divine, París, Payot, 1974, junto a los capítulos de Ch. Kérényi dedicados a la infancia en la mitología clásica, entre los que figura el apartado "L'enfant orphelin», particularmente útil para el tema del abandono; Nicole Belmont, Les signes de la naissance, Paris, Librairie Plon, 1971, sobre los nacimientos excepcionales; C. M. Bowra, Heroic Poetry, Londres, MacMillan, 1961, en especial el vol. I, págs. 94-97, para la infancia heroica, y el capitulo titulado «The Wonder Child» de C. Grant Loomis, White Magic. An Introduction to the Folklore of Cbristian Legend, Cambridge, The Medieval Academy of America, 1948, págs. 15-26, para la niñez hagiográfica; el clásico de Lord Raglan (F. R. Somerset), The Hero. A Study in Tradition, Myth and Drama, Westport, Conneticuct, Greenwood Press, 1975, reimpr. de la ed. de Nueva York, 1956, y «The Hero of Traditionw, en The Study of Folklore, ed. Alan Dundes, Englewood Cliffs, Prentice Hall, 1965, págs. 142-157, que es reimpresión de Folklore, XLV, 1934, págs. 212-231. Es fundamental para este tema aplicado a la materia artúrica, concretamente al nacimiento de Lancelot, el artículo de Nenad Ivić, «Epiphanie du héros», Studia Romanica et Anglica Zagrabiensia, XXIX-XXX, 1984-1985, págs. 191-227, donde se relaciona la infancia de Lancelot con «Le scénario des débuts de la carrière du héros indo-européen», en que el rito de iniciación es precedido por una suerte de epifanía del héroe que tiene lugar en el lago; y el de Laurence Harf-Lancner, «Lancelot et la Dame du LaC», Romania, CV, 1984, págs. 16-33. En cuanto a los estudios que han aplicado el esquema heroico a las biografías artúricas, 
sos personajes artúricos ${ }^{3}$. La infancia de Esplandián está trazada cuidadosamente como la de buena parte de los mitos, pues son sus circunstancias, junto a su linaje, razón y a la vez causa de su personalidad adulta. Es por ello por lo que, al constituir la religiosidad su rasgo distintivo, tales motivos aparecen teñidos de significación cristiana; y por lo que ya desde la primera mención a Naciano, incluso antes, a partir del momento en que aparece la leona, el relato adquiere el ambiente que caracteriza buena parte del "roman" artúrico en prosa, y lo convierte, en definitiva, en el primer paso para que la caballería de Amadís se divinice en Esplandián como harán evidente las Sergas ${ }^{4}$.

debe tenerse en cuenta el clásico de Alfred Nutt, «The Aryan expulsion-and-return-formula in the Folk and Hero Tales of the Celts», The Folklore Record, IV, 1881, págs. 1-44, que aunque está dedicado a los cuentos celtas observa puntos en común con la materia de Bretaña; el apartado que Marie-Luce Chênerie dedica a «La tradition héroïque et les contes populaires» en Le chevalier errant, Ginebra, Droz, 1986, págs. 63-74; Juan Bautista Avalle-Arce, «El Amadis primitivo», en Actas del Sexto Congreso Internacional de Hispanistas, Toronto, 1977, University of Toronto, 1980, págs. 79-82, para la biografía de Amadís. El mejor estudio acerca de la crianza fuera del hogar sigue siendo el de François Kerlouegan, «Essai sur la mise en nourriture et l'éducation dans les pays celtiques d'après le témoignage des textes hagiographiques latins», Études Celtiques, XII, 1968-1969, páginas 101-146.

2 J. B. Avalle-Arce, «El nacimiento de Amadis», en Essays on Narrative Fiction in the Iberian Peninsula in Honour of Frank Pierce, Oxford, The Dolphin Book, 1982, págs. 15. 25; Juan Manuel Cacho Blecua, intr. a su ed. del Amadis de Gaula, Madrid, Cátedra, 1987, vol. I, págs. 136-140, y Jole Scudieri Ruggieri, «A proposito di Amadís Sin-Tiempon, Cul. tura Neolatina, XXVIII, 1968, págs. 261-263.

3 Sobre el nacimiento de personajes artúricos pueden consultarse, además de los artículos de Nenad Ivić y Laurence Harf-Lancner citados, los estudios siguientes: «The Lake and Arthurian Magic» de Elspeth Kennedy, cap. V de Lancelot and the Grail. A Study of the Prose Lancelot, Oxford, Clarendon Press, 1986, págs. 111-142, que es el mejor análisis sobre la infancia de Lancelot; y Anne Berthelot, «La "merveille" dans les enfances Lancelot», Médiévales, VII, 1985, págs. 86-102, para el mismo tema. A. H. Krappe, «La naissance de Merlin», Romania, LIX, 1933, págs. 12-23, para el nacimiento de Merlín; y Alan Fedrick, «The account of Tristan's Birth and Childhood in the French Prose Tristan», Romania, LXXXIX, 1968, págs. 340-354, para el de Tristan. Raymond H. Thompson, *Gawain Against Arthur: The Impact of a Mythological Pattern upon Arthurian Tradition in Accounts of the Birth Gawain», Folklore, LXXXV, 1974, págs. 113-121, para el nacimiento de Gauvain y su relación con el mito de Edipo; Roger Sherman Loomis, «The Kingship of Gawain, pope Gregory and Mordredw, Celtic Myth and Artburian Romance, Nueva York, 1927, págs. 331-343, para el nacimiento de Gauvain y su parentesco con diversas leyendas celtas; Amy Varin, «Mordred, King Arthur's Son», Folklore, XC, 1979, págs. 167-177, para el de Gauvain y Mordred, y su deuda con la historia del celta Gwri y la leyenda del papa Gregorio, y Paloma Gracia, Las señales del destino beroico, Barcelona, Montesinos, 1991.

- Samuel Gili y Gaya, «Las Sergas de Esplandián como crítica de la caballería bretona», en Boletín de la Biblioteca Menéndez Pelayo, XXIII, 1947, págs. 103-111, y José Amezcua, «La oposición de Montalvo al mundo del Amadis de Gaula», Nueva Revista de Filología Hispánica, XXI, 1972, págs. 320-337. Véase J. B. Avalle-Arce, Amadís de Gaula: el primitivo y el de Montalvo, México, FCE, 1990, págs. 398-401, sobre el Nasciano de una y otra versión. 
Nasciano es uno de los personajes más complejos del Amadis de Gaula. Su protagonismo resulta notable en extremo desde la primera intervención y hasta el término de la obra, aunque la frecuencia con que participa en el desarrollo argumental es escasa. Sin embargo, el influjo que ejerce sobre los personajes más relevantes es muy profundo y es mucha, en consecuencia, la trascendencia de sus actos; además, está dotado de una naturaleza tan extraordinaria que imprime una atmósfera singular a los episodios en que toma parte. En cuanto a su tradición, ésta es, en primer lugar e inequívocamente, la del eremita artúrico - uno de los personajes secundarios más habituales y, a la par, de mayor significación ${ }^{5}$-; figura con la que entronca directamente, ya que deriva de Nascien, un ermitaño que, como Nasciano, tiene visos

5 Véase para la función del ermitaño en la literatura artúrica: Angus J. Kennedy, «The Hermit's Role in French Arthurian Romance (c. 1170-1530)», Romania, XCV, 1974, páginas $54.83, \ll(\ldots)$ the Hermit is given a two-fold role to play: on the one hand, that of a benevolent utility-figure, who performs a wide variety of minor services for knight-errantry, and on the other, and more important by far, that of a didactic figure, who acts either as the vigorous exponent of Christian chivalry, or else as the critic of contemporary Christianity», pág. 55; en «The Portrayal of the Hermit-Saint in French Arthurian Romance: The Remoulding of a Stock-Character», An Arthurian Tapestry. Essays in Memory of Lewis Thorpe, ed. Kenneth Varty, University of Glasgow, 1981, págs. 69-82, da cuenta de los motivos que pueden ser identificados en la figura del ermitaño, distinguiendo tres categorías en las que engloba un número de elementos estereotipados y divulgados a partir de las Vitae Patrum, otros procedentes de la observación de la realidad contemporánea y finalmente los propios de la fantasía del universo artúrico; afirma que tiene un interés especial «a number of psycological ties which the reader is invited to detect between the knight and the Hermit-Saint as a member (or ex-member) of the chivalric class and the concern to stress the importance and distinction of the lineage to which he directly or indirectly belongs». Pierre Jonin, en «Des premiers ermites à ceux de la Queste del Saint Graal», Annales de la Faculté des Lettres et Sciences Humaines d'Aix, XLIV, 1968, páginas 293-350, confronta los ermitaños de la Queste con sus modelos de las Vitae Patrum, son muchos los rasgos coincidentes; sin embargo, la mayor diferencia hay que buscarla en que los eremitas literarios mantienen una relación con sus contemporáneos que los reales rehuyeron. También pueden consultarse los estudios de Danielle Buschinger, $*$ Le rôle de l'ermite chez Béroul, Eilhart et les dérivés du Tristrant allemandw, en Exclus et systèmes d'exclusion dans la littérature et la civilisation médiévales, Senefiance, 5, Aix-en Provence-, Cuerma, 1978, págs. 267-280, sobre el ermitaño que intercede ante Marc para que Tristan e Iseut sean perdonados; el de Anna Maria Finoli, «La figura dell'eremita nella letteratura antico-franceses, L'eremitismo in Occidente nei secoli XI e XII, Atti de la seconda settimana internazionale di studio, Mendola, 1962, Milán, 1965, págs. 581-591, que es una visión de conjunto sobre la presencia de eremitas en la literatura francesa medieval, pero se ocupa especialmente de la literatura artúrica, y, en particular, de Li contes del Graal y la Vulgata; el de Mário Martins, «A prioridade eremítica en la Queste», Itinerarium, XX, 1974, págs. 3-25; y el de Jean-Charles Huchet, «Les déserts du roman médiéval, Le personnage de l'ermite dans les romans des $\mathrm{xII}^{\circ}$ et $\mathrm{xIII}^{\circ}$ siècles», Littérature, LX, 1985, páginas 89-108. Para el papel que el ermitaño desempeña en el Amadis de Gaula y sus continuaciones, véase Pierre Sage, Le «Bon Prétre» dans la littérature française d'Amadis de Gaule au Génie du Cbristianisme, Ginebra y Lille, Droz y Giard, 1951, cap. I, «Le prêtre des Amadis», págs. 23-39, en que relaciona a los eremitas del Amadis con los artúricos, da cuenta de los ermitaños que aparecen en cada uno de los libros, analizando sus características, además de la evolución de este tipo de personaje a lo largo del ciclo. 
de santidad: Nascien desempeña un papel importante en la Queste del saint Graal, y en la Estoire du Graal se alude a su bautismo, en que tuvo lugar un acontecimiento sobrenatural ${ }^{6}$. No obstante, existen rasgos en la personalidad de Nasciano que permiten ponerlo en relación con la hagiografía y con los evangelios apócrifos; pues, aun teniendo en cuenta la deuda que las narraciones artúricas mantienen con aquéllos, hay determinados momentos en que su comportamiento o, incluso, su sola actitud, evocan el recuerdo de tales obras $^{7}$.

La presencia de Nasciano en el Amadis surge en relación a las circunstancias que envuelven el nacimiento de Esplandián; concretamente, al hecho de que su madre decidiera abandonarlo en el monasterio de Miraflores al poco de nacer. Desde el primer momento, aparece ligado estrechamente a la geografía maravillosa que lo envuelve: "un valle tan spesso y tan esquivo, que ninguna persona a mala vez en él podría entrar, según la braveza y spessura de la montaña, y alli criavan leones y otras fieras animalias" (L. III, LXVI) ${ }^{8}$. No constituye éste un hecho extraordinario; el bosque es el medio natural de los ermitaños medievales, no sólo en la ficción sino también en la realidad histórica. El bosque se presenta como dominio de los animales salvajes y, a la vez, como un lugar de asilo, donde las normas establecidas por la sociedad no tienen vigencia y donde encuentra refugio tanto el eremita como el marginado; su sentido es ambivalente por ello, ya que constituye un espacio de exilio y, al mismo tiempo, un espacio donde el contacto con el misterio es una práctica cotidiana, una puerta abierta al otro mundo cuyas leyes

B Una relación exhaustiva de las novelas artúricas donde Nascien aparece se halla en G. D. West, An Index of Proper Names in French Arthurian Prose Romances, University of Toronto Press (Romance Series, 35), 1978, págs. 230-231, y An Index of Proper Names in French Arthurian Verse Romances 1150-1300, University of Toronto Press (Romance Series, 15), 1969, pág. 121, donde se recogen, además, las diversas teorías que se han dado acerca del origen de su nombre. Para la procedencia del nombre Nascien, véase J. Douglas Bruce, *Galahad, Nascien, and Some Other Names in the Grail Romances», Modern Language Notes, XXXIII, 1918, págs. 129-137; en las págs. $134-135$ se ocupa de Nascien, del que afirma: "Nascien", "Nassien" is derived evidently (...) from "Naasson", which figures in the genealogy of Christ, St. Matthew, I, 4-also, St. Luke, III, 32», pág. 134.

7 La tradición apócrifa no es ajena a la literatura artúrica, como ha demostrado $\mathrm{Ha}$ rry F. Williams en «Apocryphal Gospels and Arthurian Romance», en Zeitschrift für Romanische Pbilologie, LXXV, 1961, págs. 124-131. Sobre hagiografía y literatura artúrica puede consultarse Roger Sherman Loomis, «Les légendes hagiographiques et la légende du Graal», en Les Romans du Graal aux XII' et XIII' siecles, Paris, CNRS, 1956, págs. 233. 247, donde desarrolla la idea de que la cristianización de la leyenda del Graal evoluciona paralelamente a las leyendas hagiográficas; C. Grant Loomis, «King Arthur and the Saints», Speculum, VIII, 1933, págs. 478-482, y Ronald Tamplin, «The Saints in Sir Gawain and the Green Knight», Speculum, XLIV, 1969, págs. 403-420.

8 Amadis de Gaula, ed. de Juan Manuel Cacho Blecua, Madrid, Cátedra, 1988, tomo II, pág. 1005; pág. 55 de la ed. de J. B. Avalle-Arce, Madrid, Espasa-Calpe, 1991, vol. II. 
escapan a la razón ${ }^{9}$. Además, la entrada de Esplandián en este ámbito se produce a partir de su extravío en una fuente, motivo asimilable en determinados casos a un río, y a la frontera entre dos mundos en consecuencia ${ }^{10}$; o puede, incluso, por lo que tiene de valor femenino, equipararse a un lago maternal, al espacio propicio para que una vida de excepción pueda tener comienzo, para que se produzca un segundo nacimiento, ineludible en la forja de un héroe como será Esplandián ${ }^{11}$ :

$\mathrm{Y}$ en somo deste valle havía una pequeña hermita antigua en que morava aquel Nasciano hermitaño, que por muy santo y devoto hombre de todos era tenido, y acatado en tanto, que era opinión de las gentes comarcanas que algunas vezes era de celestial manjar governado (L. III, LXVI) ${ }^{13}$.

En este punto, el relato abandona definitivamente el espacio cortesano para situar la narración en un ambiente completamente distinto, maravilloso;

9 Jean Charles Payen, «L'homme devant la nature. La forêt», en Littératurc française. Le Moyen Age, Parfs, Arthaud, 1970, cap. I, págs. 57-58. Véase para desierto y eremitismo en general, asf como para el significado del desierto en la literatura artúrica: Jacques Le Goff, «El desierto y el bosque en el Occidente medieval», en Lo maravilloso y lo cotidiano en el Occidente medieval, Barcelona, Gedisa, 1985, págs. 25-39, y «Lévi-Strauss en Brocé liande», en L'imaginaire médiéval, Paris, Gallimard, 1985, págs. 151-187, donde analiza la significación del bosque del Y vain, además de las figuras que están intimamente ligadas a él: el ermitaño y el león; así como el apartado que MarieLuce Chênerie dedica a «La forêt», págs. 147-160 de Le chevalier errant, ed. cit.

10 Marie-Luce Chênerie, «Le motif de la "fontaine" dans les romans arthuriens en vers des $\mathrm{xII}^{*}$ et $\mathrm{xIII}^{*}$ siècles», en Mélanges de langue et littérature françaises du Moyen Age et de la Rennaissance offerts a Charles Foulon, Rennes, Université de Haute-Bretagne, 1980, tomo I, págs. 99-104. Véase también Roger Sherman Loomis, Arthurian Tradition and Chrétien de Troyes, Nueva York, Columbia University Press, 1949, cap. XLIX, «The fountain», págs. 289-293, y William A. Nitze, «Yvain and the Myth of the Fountain», Speculum, XXX, 1955, págs. 170-179, para la fuente del Yvain; Anne Berthelot, ${ }^{\circ} \mathrm{Du}$ lac à la fontaine: Lancelot et la fée-amante», Médiévales, VI (1984), págs. 5-17, para el episodio del hada y la fuente envenenada en el Lancelot en prose; Antoinette Saly, ${ }^{2}$ Motifs folkloriques dans le Lancelot de Chrétien de Troyesw, en Bulletin Bibliographique de la Societé Internationale Arthurienne, XXX, 1978, págs. 187-195, en que trata la relación entre el folclore de las aguas, la fuente y el episodio en que Lancelot encuentra el peine de marfil de Guenièvre; Gérard Chandès, «Recherches sur l'imagerie des eaux dans l'oeuvre de Chrétien de Troyes», Cabiers de Civilisation Médiévale, XIX, 1976, págs. 151-164, y Micheline Combarieu du Gres, «L'eau et l'aventure dans le cycle du Lancelot-Graal», en L'eau au Moyen Age. Senefiance, 15, Aix-en-Provence, Publications du CUERMA, Université de Provence, 1985, págs. 111-147. Para las fuentes en el folclore, véase Paul Sébillot, Le folklore de la France. Les eaux douces, París, Imago, 1983; asI como C. B. Le wis, The Origins of the Wearing Songs and the Theme of the Girl at the Fountain», Publications of the Modern Language Association, XXXVII, 1922, págs. 141-181, para las que la lírica tradicional presenta.

11 Joseph Campbell, El héroe de las mil caras, México, FCE, 1972, especialmente las págs. 286-287.

12 Amadis de Gaula, ed. cit. de J. M. Cacho Blecua, vol. II, pág. 1005; pág. 55 de la ed. cit. de J. B. Avalle-Arce, vol. II. 
pero no al modo de la geografía fantástica de la Insola Firme, por ejemplo, sino a la manera de los desiertos que aparecen en las vidas de santos o en los Evangelios apócrifos, lo que se hace evidente por el comentario de la alimentación divina que sustenta a Nasciano, y por la actitud respetuosa de los animales salvajes: "Y cuando el comer le faltava, ívalo buscar por la tierra, sin qu'el león ni otra animalia alguna mal le fiziesse, ahunque muchos dellos, yendo en su asno, continuamente encontrava; ante, semejava que homildança le fiziessen" (L. III, LXVI) ${ }^{13}$.

El valle es un sitio inhóspito sólo aparentemente; la condición de Nasciano hace que, por el contrario, sea en la realidad un espacio de atmósfera serena, en donde los animales salvajes se rinden ante la evidencia de su superioridad ${ }^{14}$. Por añadidura, esta atmósfera serena se inunda de calidez con las palabras que completan la descripción de las relaciones que el ermitaño mantiene con las bestias ${ }^{15}$ :

Y cerca desta hermita havía una cueva entre unas peñas donde una leona sus fijos pequeñuelos criava; y muchas vezes el hombre bueno los visitava y dava de comer, cuando lo tenía, sin temer la leona; antes ella, cuando con ellos le veía, se apartava dende hasta que él se iva. Con estos leonçillos, después que

13 Ibid. Jean Bichon en L'animal dans la littérature française au XII' et au XIII' siècles, Université de Lille, III, 1976, vol. I, pág. 105, alude a estos desiertos literarios medievales en que moran bestias salvajes, y observa que en las Viate Patrum aparecen animales característicos de Oriente como los leones, además de algunos mitológicos, mientras que las vidas francesas de santos presentan animales propios de los bosques europeos, junto a otros fantásticos; ténganse en cuenta los comentarios y aportaciones que Jean $\mathrm{Du}$ fournet hizo a este estudio en "L'animal dans la littérature française au $\mathrm{xII}^{\circ}$ siècle et au XII' siècle», Revue des Langues Romanes, LXXXIII, 1978, págs. 327-344. Para Ernst Robert Curtius, Literatura europea y Edad Media Latina, México, FCE, 1976, cap. X, la presencia de leones en la literatura medieval es producto de los ejercicios retóricos medievales y, por tanto, de la tradición literaria, págs. 264-265.

14 Un episodio perteneciente a uno de los evangelios apócrifos apunta el carácter religioso de la tradición en la que mejor puede emplezarse la escena de Nasciano subido en su asno y reverenciado por los animales; me refiero al que narra el paso por el desierto de José y María llevando a Jesús hacia Egipto, en que según el Evangelio del Pseudo Mateo: «(...) los leones y leopardos le adoraban e iban haciéndoles compañía en el desierto. Adondequiera que Marfa y José dirigieran sus pasos, ellos les precedían, enseñándoles el camino. E inclinando sus cabezas adoraban a Jesús», XIX,1, traducción de Aurelio de Santos Otero, Los Evangelios Apócrifos, Madrid, La Editorial Católica, 1966, pág. 231. En su ob. cit., Jean Bichon hace referencia a varios pasajes de obras francesas medievales en que los animales salvajes muestran una sumisión parecida a diversos santos, págs. 111-112.

15 Acerca de la marginalidad del eremita y la relación con los animales, Lucille Guilbert afirma en «L'animal dans la Légende dorée», Legenda Aurea: sept siècles de difussion. Actes du colloque international sur la Legenda Aurea, Montréal, 1983, Montreal y París, Bellarmin y J. Vrin, 1986, págs. 77-89: «L'animal identifie donc ce marginal élu comme fou et saint. Le héros de la foi vit une marginalité positive qui opère le renversement des valeurs prônées par le monde. Le saint avec l'animal est réintroduit dans le projet d'un monde réharmonisé», pág. 85. 
havía sus horas rezado, passava su tiempo, haviendo plazer de los ver trebejar por la cueva (L. III, LXVI) ${ }^{16}$.

Por otra parte, la imagen del ermitaño alimentando a los cachorros de la leona y dedicando sus horas a verlos jugar por la cueva contribuye a hacer de la floresta un lugar de orden, un orden anti-natural, maravilloso o, mejor, maravilloso-cristiano, que lo hará propio para la crianza de un héroe de las características de Esplandián. Además, este pasaje pone en evidencia que se trata de un lugar opuesto al castillo de Miraflore ${ }^{17}$, un mundo real en el que el pequeño es separado de su madre por voluntad de ésta, y puesto en riesgo para ponerse ella a salvo. La actitud del ermitaño hacia la leona y sus leoncillos sirve de contrapunto a la de Oriana, pues parece que los sentimientos maternales son patrimonio de los seres que habitan la floresta.

A medida que avanza el relato aumenta a la vez la impresión de que la religiosidad es cada vez más poderosa, ya sea por causa de Nasciano, de Esplandián, o bien por el ambiente propio de la floresta; de que el cristianismo es el valor máximo por encima de la caballería o de la aventura, que son relegadas ahora a un segundo plano. El antecedente artúrico es evidente con solo tener en cuenta el espíritu de la Queste o de la Estoire du Graal; y todo ello se hace particularmente obvio en el momento en que las alusiones a Nasciano dan paso a su presencia directa en la obra, cuando al alba y por mediación de Dios interviene para salvar a Esplandián, que había sido arrebatado por la leona para servir de sustento a sus cachorros ${ }^{18}$ :

16 Amadis de Gaula, ed. cit. de J. M. Cacho Blecua, vol. II, págs. 1005-1006; ed, cit. de J. B. Avalle-Arce, vol. II, pág. 55. Otra vez, un fragmento de la obra del Pseudo Mateo permite entroncar el pasaje con la tradición que bien puede hallarse tras este texto, esto es, el evangelismo apócrifo o la literatura hagiográfica medieval, repleta de escenas en que los santos son reverenciados por animales: «Teniendo, pues, Jesús, la edad de ocho años, salió una vez de Jericó con dirección al Jordán. A la vera del camino, muy cerca ya de las márgenes del río, habla una madriguera, donde una leona criaba sus cachorros. (...) Llegó, pues, Jesús al lugar, a sabiendas de que en aquella caverna había parido la leona sus crías. A la vista de todos entró en la cueva. Los leoncitos, que le vieron, corrieron a El y le adoraron. Jesús se sentó en medio de la gruta, y ellos correteaban en torno suyo, acariciándole y jugueteando, mientras que los leones más viejos estaban retirados cabizbajos, haciéndole fiestas con la cola» (Evangelio del Pseudo Mateo, XXXV, trad. cit., págs. 249-250).

$17 \alpha(. .$.$) esta selva desierto. Se opone al «mundo», es decir, a la sociedad organizada,$ a la corte, por ejemplo, en la novela cortesana a la corte de Arturo. (...) En la literatura, expresión privilegiada del simbolismo de una sociedad, comprobamos sobre todo esta oposición del bosque y castillow (Jacques Le Goff, en Lo maravilloso y lo cotidiano en el occidente medieval, ed. cit., pág. 38).

18 Sturgis E. Leavitt, «Lions in Early Spanish Literature and on the Spanish Stagex, Hispania, XLIV, 1961, págs. 272-276, traza la historia de la presencia del león en la literatura castellana; alude a su aparición en el Poema de Mio Cid, en la Vida de Santa María Egipciaca, donde un león ayuda a un ermitafio a cavar una tumba para María; en El libro del Caballero Zifar, y en Palmerin de Inglaterra. La Vida de Santa Maria Egipciaca cuenta 
(...) y esto era ya a tal sazón que el sol salía. Mas aquel Señor del mundo (...) acorriólo en esta guisa: que haviendo aquel Santo Nasciano cantado missa al alva del día, y yéndose a la fuente por folgar af, que la noche havía sido muy calorosa, vio cómo la leona llevava el niño en su boca (L. III, LXVI) ${ }^{19}$.

Nasciano santiguó al muchacho y mandó a la leona que dejara a la criatura y se retirara, a lo que obedeció muy mansa ${ }^{20}$. La bestia se sometió a la voluntad de Nasciano y, más tarde, al ver que daba de mamar a sus leoncillos, le ordenó que alimentara a Esplandián, por lo que fue criado con la leche de una leona cuya naturaleza Nasciano había desembravecido milagrosamente.

El relato incluye en este pasaje dos motivos de amplísima tradición: uno es el tema del león manso, ya sea por agradecimiento o amansado con la sola palabra humana; es muy frecuente, e integra diversas vidas de santos ${ }^{21}$.

la historia de la santa - una prostituta arrepentida-, y su penitencia en el desierto, ubicado justo después de pasar el río Jordán, que marca el paso a otro mundo. Allí permanece hasta su muerte, alimentada por tres panes durante años; al acabarse éstos, por yerbas: y «Después viscó veynte que non comi6, / si el ángel non gelo dio», vv. 776-777, ed. Manuel Alvar, Madrid, CSIC, 1972, vol. II, pág. 79.

10 Amadís de Gaula, ed. cit. de J. M. Cacho Blecua, vol. II, pág. 1007; ed. cit. de J. B. Avalle-Arce, vol. II, pág. 56.

20 Lucille Guilbert afirma en el art. cit.: \&Il détient un pouvoir solide sur les animaux: il expulse les animaux malfaisants tels les serpents, il convertit des loups en animaux domestiques, il punit l'animal récalcitrant, et aussi, il noue amitié avec eux, il étend son emprise bénéfique sur le règne animal, il protège les bêtes et les nourrit. (...) Les métaphores des loups qui se jettent sur les brebis ou du loup (ou lion) change en agneau se colorent d'une signification puissante, lorsque les bêtes féroces se soumettent au saint alors que l'homme résiste. (...) Ce pouvoir de conversion et de renversement radicaux du fauve affamé constitue l'une des plus grandes preuves de la puissance du saint ou de la sainte», pág. 81. C. Grant Loomis sostiene, refiriéndose a las relaciones de santos y ermitaños con animales salvajes: «The earliest accounts of animal miracles are found among the fathers of the desert. The fauna is characteristic of the region. The divine quality of a holy person was recognized by a hungry lion»; y menciona a continuación numerosos ejemplos de casos que evidencian los lazos que unen a los santos con los leones: «Lions licked the moisture from the face and feet of Eleutherus, although they had previously slain a great many pagans. Lions in England seem strange to us. Finan carried some cubs in his bosom, while the father and mother followed him, and all the people were amazed. Lions served as guides for Dominicus and Abba 'Eulog. Daria was protected in a brothel by a lion which kept the door and drove off the men who attempted to approach the virgin. John the Silent was unharmed by a lion which found him sleeping. Simeon Priscis entertained two of the animals, and lions protected the bodies of Bacchus and Sergius. The same creatures helped bury Paul of Thebes and Mary of Egypt. Gerasimus, Aninas, and Jerome removed thorns from the feet of grateful lions. Gerasimus' lion used to watch the monastery's ass. One day, the lion neglected his charge, and the beast was stolen. Whereupon, the royal animal submitted to do the duties of the ass. Later, the lion met the thief and recaptured not only the ass but some camels and drove them to the monastery. When the saint died, the lion pined away with grief upon his friend's grave. In the legends of Zosimus, Paul, and others, we hear of lions which talk» (ob. cit., págs. 58-59).

21 Para un estudio exhaustivo de la tradición del «león reverente», un tipo determinado de león manso, y su papel en la hagiograffa, véase Miguel Garci-Gómez, *La tradición del león reverente: glosas para los episodios en Mio Cid, Palmerín de Oliva, Don Qui- 
Tampoco es éste un motivo ajeno a la literatura artúrica, que lo había incorporado a diversas obras: está presente en el Yvain de Chrétien de Troyes $^{22}$, y en la Queste inmerso en un contexto simbólico-religioso ${ }^{23}$. El se-

jote y otros», Kentucky Romance Quarterly, XIX, 1972, págs. 255-284; recogido en «Mio Cid». Estudios de endocrítica, Barcelona, Planeta, 1975, págs. 172-206. Miguel GarciGómez lo define como «el león que se muestra civilizado, mesurado, humilde, zalamero, avergonzado, etcétera, en presencia de un personaje extraordinario, en acatamiento y testimonio de su carisma, numen, gracia, virtud, cualidad sobrehumana, divina» (págs. 255256), y analiza su presencia en la literatura clásica, bíblica y romance - Mio Cid y Palmerín de Oliva, entre otras obras-. En el Libro de los exenplos se cuenta que un león que se había clavado una espina fue a un «rrustico» para que se la sacara; éste lo hizo y la fiera «abaxada la cabeça, por señales diole gracias empero sienpre se acordo del bien que avia rrescebido». Pasado el tiempo el animal fue llevado a Roma, a la vez que el hombre, por haber cometido un crimen, era entregado a los leones; entre éstos estaba aquel al que había sacado la espina que «conosciolo luego e acordosse del bien fecho, e primero que ninguno de los otros corrio para el, e abaxada la cabeça, començole a lavar los pies e mirandolo todo el pueblo, e guardolo de las otras bestias que non le feziessen mal» (ed. cit. de J. E. Keller, núm. 186, pág. 149; núm. 115, pág. 474 de la ed. de Pascual Gayangos). Se trata de la historia de Androcles, cuya fuente es la Gesta Romanorum y Jacobo de Vitry, según A. H. Krappe, «Les sources du Libro de los exemplos», Bulletin Hispanique, XXXIX, 1937, págs. 5-54. El mismo libro se hace eco del tema cuando narra cómo una leona acató la orden de un discípulo del abad Paulo, anécdota que se incluye para ilustrar la lección de que «al santo ombre todos los ombres cognosçen; al obediente todos lo obedesçen» (ed. John Esten Keller, Madrid, CSIC, 1961, núm. 317, pág. 248) (251 de la ed. de Pascual de Gayangos, Madrid, Rivadeneyra [BAE, 51], 1884, pág. 509). A. H. Krappe señala como fuente las Vitae Patrum, Liber III, ed. J.-P. Migne, tomo LXXIII de su Patrologia Latina, col. 756. El motivo se recoge también en la leyenda de San Eustaquio, tanto en la versión castellana - De un cavallero Plácidas- como en las francesas: German Knust, Dos obras didácticas y dos leyendas, Madrid, Ginesta, 1878, pág. 154; La Vie de Saint Eustache. Poème français du XIII siècle, ed. Holger Petersen, París, Champion, 1928, vv. 1.871-1.876, pág. 67, y La Vie de Saint Eustace. Version en prose trançaise du XIII' siècle, ed. Jessie Murray, Parls, Champion, 1929, cap. XXXVI, págs. 40-41. El Amadís de Gaula presenta un caso de «tradición inversaw: Amadís renuncia a dar muerte a los leones, cuya liberación ha supuesto poco antes y en la práctica la salvación de su vida; se trata del episodio en que Briolanja suelta a dos leones para que Amadís, acosado por las gentes de su propio castillo, pueda escapar. Para Juan Manuel Cacho, si bien la tradición literaria hace del animal el ser agradecido, «en esta ocasión, por el contrario, será el héroe quien sabrá agradecer a los leones su ayuda, invirtiendo la tradición y dando por tanto "exemplum" de comportamiento» (nota 25, pág. 464 de su ed. cit. del Amadis de Gaula, vol. I).

${ }_{22}$ Para el león del Yvain, véase Julian Harris, «The Rôle of the Lion in Chrétien de Troyes' Yvain», Publications of the Modern Language Association, LXIV, 1949, págs. 11431163, y Norris J. Lacy, «Yvain's Evolution and the Role of the Lion», Romance Notes, XII, 1970, págs. 198-202, que rebate la opinión del anterior, según la cual el valor fundamental del león de Yvain estriba en ser símbolo de Cristo; para él: «the animal should be seen "first" as a personification of Yvain's ideal - responsibility, devotion, and servicerather than as a symbol of Christ" (pág. 202). Según Roger Sherman Loomis, «The Grateful Lion», cap. LIII de Arthurian Tradition and Chrétien de Troyes, ed. cit., págs. 311-317, los tratamientos mejores del tema los han dado Th. M. Chotzen, «Le lion d'Owein (Yvain) et ses prototypes celtiques», Neophilologus, XVIII, 1933, págs. 131-136, y A. G. Brodeur, \&The Grateful Lion: A Study in the Development of Mediaeval Narrative», Publications of the Modern Language Association, XXXIX, 1924, págs. 485-524. Más recientemente, 
gundo es el del amamantamiento por animales, característico de las infancias heroicas, mitológicas ${ }^{24} \mathrm{y}$ medievales de todo signo, en las que aparece ge-

Juliette de Caluwé-Dor ha dedicado un trabajo a la cuestión titulado «Yvain's Lion Again: A Comparative Analysis of Yvain's Personality and Function in the Welsh, French and English Versions», An Arthurian Tapestry, ed. cit., págs. 229-238, en que muestra cómo su función es diferente en cada una de las diversas versiones, en relación al tema de la obra. En el índice de motivos folclóricos de Anita Guerreau, «Romans de Chrétien de Troyes et contes folkloriques. Rapprochements thématiques et observations de méthode», Romania, CIV, 1983, págs. 1-48, el león del Y vain aparece registrado según las diversas entradas a las que se ajusta. De forma significativa, entre las correspondencias aproximadas, incluye el motivo B 251.2.11 «Lion lies down at feet of saint», sobre el que Anita Guerreau comenta: "Le lion marque de même sa reconnaissance à Yvain» (pág. 42). Debe tenerse en cuenta también el artículo de Francis Lee Utley, «Arthurian Romance and International Folktale Method», Romance Pbilology, XVII, 1964, págs. 596-607, que hace referencia al león del Yvain en pág. 600.

23 El diablo abandona a Perceval en una isla poblada únicamente por bestias salvajes; sabe que sólo la ayuda divina puede salvarlo, y recuerda a Daniel enfrentado a los leones. Se dirige hacia una montaña cuando ve a una serpiente que arrastra la cría de una leona, y más adelante, mientras lucha con un león adulto, da muerte al reptil. Hecho esto, el león «viene y baja la cabeza haciendo el mayor gozo que puede»; después deja a Perceval para llevar el cachorro a su guarida, y regresa a su lado: «no parecía que quisiera hacerle daño, sino que se le acercó con muestras de gozo. Cuando Perceval lo ve lo llama y viene hasta él estirando el cuello y la cabeza. El león se queda ante él como si fuera el animal más manso del mundo; se acuesta delante y le apoya la cabeza en el hombro y espera así que la noche llegue oscura y negra; se duerme ante el león (...)» (trad. Carlos Alvar, Madrid, Editora Nacional, 1980, cap. LXX, págs. 127 y 128-129; pág. 94, 1. 30-31, y 96, 1. 25-29, de la ed. Albert Pauphilet, París, Champion, 1949). En el capítulo que Jean Bichon -ob. cit., vol. II - dedica a las bestias en la literatura religiosa, incluye un apartado sobre el animal alegórico en la Queste donde analiza la significación de este episodio: «Le lion et le serpent», págs. 575-580. El motivo se recoge también en la tradición épica tardía, en Florent et Octavian, por ejemplo, en que una leona sustrae a uno de los hijos de Florimonde mientras duerme en un bosque, lleva al pequeño a su guarida, donde juguetea con él, lo lame y lo acaricia, momento a partir del cual no se separará de Octavian (Paulin Paris, «Florent et Octavian», Histoire Littéraire de la France, Parfs, H. Welter, 1898, vol. XXVI, cap. XIII, págs. 303-335, y Léon Gautier, Les épopées françaises, París, H. Welter, 1892, vol. II, pág. 497; en pág. 482 se refiere a Bauduin de Sebourc, donde aparece también una suerte de león reverente). Según A. H. Krappe, «Florent et Octavian», Romania, LXV, 1939, págs. 359-373, el león amaestrado es un lugar común en la literatura a partir del siglo xII, cuando los cruzados vieron en el Próximo Oriente tales animales.

24 Según la mitología clásica, Rómulo y Remo fueron amamantados por una loba, como Mileto, que fue expuesto junto a un árbol y alimentado por unas lobas, al igual que Licasto y Parrasio, abandonados en el monte Erimanto a causa del temor que su madre sentía por haber dado a luz gemelos; Hipotoonte fue abandonado en un bosque en dos ocasiones y amamantado por una yegua dos veces también, al igual que Neleo y Pelias, a los que Posidón envió una yegua al ser expuestos por su madre; en una de las tradiciones acerca del nacimiento de Asclepio se relata cómo éste había sido abandonado en Epidauro y amamantado por una cabra; el padre de Atalanta dejó a su hija en el bosque porque únicamente querfa hijos varones, una osa la amamantó; Télefo, según una de las tradiciones de su nacimiento, fue expuesto en el monte Partenio, y amamantado por una cierva, al igual que Auge, de quien se narra en alguna versión de su leyenda que una cierva la crí cuando fue expuesta en la montaña; finalmente, una tradición de la infancia de Paris hace 
neralmente unido al motivo de la exposición ${ }^{25}$; incluso pasó a formar parte de la hagiografía, aplicado a individuos adultos ${ }^{26}$. La particularidad de Esplandián revela el sentido en que se produjo la evolución de este tema, pues sólo después de un período de transición - así ocurre en nuestro texto en que el niño es alimentado por una bestia y por un ama- la mujer sustituyó al animal en el amamantamiento del héroe ${ }^{27}$.

referencia a que fue abandonado y amamantado por una osa (Pierre Grimal, Diccionario de mitología griega y romana, Barcelona, Labor, 1965).

${ }_{25}$ Además de integrar buena parte de las infancias heroicas en las distintas mitologías, el motivo se halla presente en obras medievales de diverso carácter: una cierva amamanta a los siete hijos del conde Eustacio e Isomberta en La Gran Conquista de Ultramar, I, LVI, vol. I, págs. 93-94, de la ed, de Louis Cooper, Bogotá, Publicaciones del Instituto Caro y Cuervo, 1979; una leona cría a Lion en Lion de Bourges. Poème épique du $X I V^{*}$ siecle, ed. de William W. Kibler, Jean Louis G. Picherit y Thelma S. Fenster, Ginebra, Droz, 1980, vv. 441-448, vol. I, pág. 16; una sirena amamanta a Tristan según el Tristan de Nanteuil, y una osa a Orson en Valentin et Orson, Paulin Paris, ob. cit., vol. XXVI, cap. X, págs. 229-269; Keith V. Sinclair, Tristan de Nanteuil, Tübingen, Max Niemeyer Verlag, 1983, págs. 13-15, y Arthur Dickson, Valentine and Orson. A Study in Late Medieval Romance, Nueva York, Columbia University Press, 1929, que establece la fuente del pasaje; para esta cuestión, véase la comunicación de Juan Manuel Cacho Blecua, «Nunca quiso mamar lech de mugier rafez (Notas sobre la lactancia. Del Libro de Alexandre a don Juan Manuel)», publicada en Actas del I Congreso de la Asociación Hispánica de Literatura Medieval, dir. Vicente Beltrán, Barcelona, PPU, 1988, págs. 209-222. La tradición alcanza al romancero hispánico en La fuerza de la sangre, ed. de S. G. Armistead y J. H. Silverman, Folk-Literature of the Sephardic Jews, Berkeley, University of California Press, 1971, t. I, pág. 286, donde la protagonista es recogida por un ermitaño y alimentada con la leche de una leona durante siete años; Janet L. Falk, "The Birth of the Hero in the Romancerow, La Corónica, XIV, 1986, págs. 220-229.

${ }^{26}$ Según la Vita sancti Egidii y La vie de saint Gilles, San Gil fue alimentado por una cierva salvaje durante su permanencia en el desierto: en oposición a Esplandián, Gil era ya adulto; pero, a semejanza de Nasciano, el pasaje revela la sumisión del animal al santo; el hecho adquiere carácter milagroso, pues San Gil había permanecido tres años en el desierto sin comer carne, pescado, ni pan, hasta la llegada de una cierva salvaje: «Gros out le piz e plein de leit: / As pez Gire se veit gesir, / Presente sei de lui servir. / Gires ad la bisse veue / $\mathrm{Ki}$ a ses pez est estendue: (...) / Tant cum iloc el deserd fud, / Del leit de la bisse ad vescud» (Guillaume de Berneville, La vie de Saint Gilles, ed. Gaston Paris y Alphonse Bos, París, Didot, 1881, vv. $1.514-1.518$ y $1.521-1.522$, págs. 46 y 47 ). Según los editores, el animal tiene la función de facilitar el que sea encontrado por alguien, que, al verlo, irá tras él hasta hallar al personaje en cuestión; como ocurre a Es. plandián, encontrado por Lisuarte cuando persegúa a un ciervo. Jean Bichon alude a otros santos a quienes determinados animales proveyeron de alimento, como Pablo Ermitaño, que fue alimentado por una nutria durante treinta años, en ob, cit., pág. 112. La Leyenda dorada presenta otros casos de eremitas alimentados por bestias, aunque no de amamantamiento: «saint Benoît reçoit sa nourriture d'un corbeau. Pendant sa vie érémitique, les oiseaux apportent à saint Blaise sa nourriture quotidienne et le saint les bénit et les guérit si d'aventure ils sont blessés (...)» (Lucille Guilbert, art. cit., pág. 84). El Libro de los exenplos inicia asf uno de sus relatos: «Un sancto ombre morava en el desierto, al qual cada dia venia una loba en la tarde e davale un pan (ed. cit. de J. E. Keller, núm. 29, pág. 49); la fuente de este pasaje se halla, según $A$. H. Krappe, «Les sources du Libro de los exemplos», ed. cit., en las Vitae Patrum, ed. cit. de J.-P. Migne.

27 Vladimir Propp, Edipo a la luz del folklore, Madrid, Fundamentos, 1980, pág. 112, donde pone como ejemplo las leyendas de Ciro, y de Rómulo y Remo. La mayorfa de estos 
En cualquier caso, tanto el motivo de la exposición como el del amamantamiento por bestias constituyen ecos de los ritos iniciáticos ancestrales, cuya superación suponía un renacimiento que preparaba al individuo para integrarse en la sociedad, o ser su gobernante, gracias a las cualidades transmitidas por el animal ${ }^{28}$ : “(...) la fiera alimenta y educa al niño, le hace ser un jefe, incluso le da una tribu, y de aquí se marcha el joven para matar al padre-jefe. (...) el protagonista, llevado a la fiera para que lo devorara, va a parar a un ambiente que conocemos por ser el del rito de la iniciación. Fue llevado al monstruo y de alli vuelve no sólo sano y salvo, sino también con los caracteres del jefe", afirma V. Propp a propósito de un cuento ${ }^{20}$; este ambiente al que se refiere es el idóneo en Esplandián, pues el bosque cuenta con un valor afín en la literatura artúrica ${ }^{30}$. "D'autre part, il arrive souvent que l'enfant soit sauvé et nourri par un animal (...). Des épreuves de ce type sont bien connues. Elles semblent avoir pour lointaine origine des croyances zoolâtriques: un enfant est prouvé appartenir au clan si l'animal du clan peut l'approcher sans lui faire

elementos que se observan en el nacimiento y crianza de Esplandián pueden ser considerados motivos folclóricos y son, por tanto, comunes a narraciones de procedencia muy variada: aś el poder mágico sobre los animales figura en el Motif-Index of Folk-Literature de Stith Thompson, Bloomington, Londres, Indiana University Press, 1966, 6 vols., como el D2156; más concretamente, el caso de Esplandián puede asociarse mejor, aunque no sea exacto, al D2156.3, el santo obliga a una bestia a devolver un niño robado a su madre; el león servicial es el B431.2 (y en el de Antti Aarne's, The Types of the Folk-Tale, Helsinki, Suomalainen Tiedeakatemia, 1928, como el tipo 156 y 590); B391 es el animal agradecido por el alimento (tipos 350, 531, 550 y 554); el B535 el animal que amamanta a un niño abandonado; el ermitaño que rescata a un niño abandonado el R131.10; la marca de nacimiento es el T563, presente en el folclore español, y el reconocimiento por una marca de nacimiento es el H51.1.

${ }^{28}$ En «el engullimiento mímico del joven por parte de los animales totémicos y en su expulsión se cela un rito. La ficción de este engullimiento era considerada, al igual que la muerte, como vuelta a la vida. La comunión con el animal totémico daba al iniciado facultades mágicas» (Vladimir Propp, ob. cit., pág. 111).

29 Ibid. A propósito del mismo tema, J. G. Frazer afirma: «En muchas tribus salvajes, especialmente entre las que se sabe que practican el totemismo, se acostumbra a que los mancebos púberes se sometan a ciertos ritos iniciáticos, de entre los cuales uno de los más comunes es la ficción de matar al mancebo y resucitarle después (...). El mancebo muere como hombre y resucita como animal; el alma animal está ahora en él y su alma humana en el animals (La rama dorada, México, FCE, 1981, págs. 775-776). Véase también el capítulo II, «Ritos de pubertad e iniciaciones tribales en las religiones primitivas» de las Iniciaciones misticas de Mircea Eliade, Madrid, Taurus, 1975, especialmente el apartado que se titula «Engullidos por un mostruo», págs. 66-70; para la literatura tiene interés el titulado «Motivos iniciáticos y temas literarios», donde dedica las págs. 207-208 a la materia de Bretaña.

30 Marie-Luce Chênerie afirma a propósito de «l'enfance sauvage» de diversos personajes como Perceval o Lancelot: «ces enfants retrouvent une condition originelle, exprimant le passage de la condition divine au statut héroïque, dans les mythes et les légendes; qu'à partir de là un renouveau peut être attendu dans la "chevalerie" qu'ils réaliseront avec un destin exceptionnel (Le chevalier errant, ed. cit., pág. 159). 
de mal", sostiene Marie Delcourt siguiendo la tesis del sentido de ordalía social o política que tuvo la que llama "exposition en montagne", y designaba en la antigüedad clásica al elegido, preparándolo a la vez para detentar el poder ${ }^{31}$. Además, el abandono y la exposición a la fiera, con el valor que ello conlleva de superación del rito iniciático, transmisión de cualidades y preparación para el mando, adquiere unas connotaciones especiales en Esplandián por tratarse de una leona, el animal asociado a la realeza por un lado, y por otro a Cristo o a $\operatorname{Dios}^{32}$; emblema de mártires y ermitaños ${ }^{33}$, a la vez que emblema de diversas casas reales.

31 Oedipe ou La Légende du Conquérant, París, Les Belles Lettres, 1981, pág. 39. A continuación dedica un apartado a desarrollar el principio que fundamenta la ordalía: "L'animal du clan reconnaît les enfants du clan», punto en que se refiere a la relación existente entre los Psilos y la «serpent cornu", a cuyas picaduras eran inmunes; lo interesante es que los Psilos probaban la legitimidad de los niños sometiéndolos a mordeduras de serpiente. «Las animalias se deven someter / al hombre justo; esto deves bien creer / Dizen que el abbad Sant Pablo tomava en las manos las serpientes cornudas que son las mas emponçoñadas que todas las otras que llaman en latin "cerastes", e escorpiones, e cortavalos por medio. E veyendo los monjes esto, maravillavansse, e preguntaronle commo podia esto ser e commo lo podia fazer. / E rrespondioles: -Qualquier que fuere linpio e sin pecado commo fue Adan en el paraisso ante que pecasse, todas cosas le eran subjugadas e les obedesçian» (Libro de los exenplos, ed. cit., John Esten Keller, núm. 237, página 186; núm. 168, pág. 487 de la ed. de Gayangos). A. H. Krappe, «Les sources du Libro de los exemplos», ed. cit., señala como fuentes las Vitae Patrum, Liber Sextus, en Patrologia Latina, ed. cit., tomo LXXIII, col. 1.002.

32 El carácter real del león aparece en cualquiera de los bestiarios medievales; véase, por ejemplo, el Llibre del Tresor de Brunetto Latini, ed. de C. J. Wittlin, Barcelona, Barcino, 1976, vol. II, pág. 78, para la versión catalana, y The Medieval Castilian Bestiary from Brunetto Latini's Tesoro, ed. Spurgeon Baldwin, University of Exeter, 1982, para la traducción castellana de la parte correspondiente al bestiario, págs. 36-38, en que se alude a la capacidad del león para resucitar a sus cachorros. «Et on set bien ke li lions resuscite son lioncel, et seit on bien comment. Car si li lionceaus naist mors, et au tierc[h] jour si vint li peres sor lui, et ensi le resuscitew ( $L i$ bestiaires d'amours di maistre Richart de Fornival e li response du bestiaire, ed. Cesare Segre, Milán y Nápoles, Ricardo Ricciardi Editore, 1957, pág. 54). La asociación del león con la figura de Cristo también es muy corriente -cfr. en Albert Pauphilet, Etudes sur la Queste del saint Graal, Paris, Honoré Champion, 1980; reimpr. de la ed. de 1921, pág. 108-, especialmente por la creencia en el poder de resurrección. En una versión catalana del bestiario toscano se traza un paralelismo entre las cualidades del león y las de Dios en el capítulo XIII, «De la natura del lé e de la sua significació», Bestiaris, ed. Saverio Panunzio, Barcelona, Barcino, 1963, vol. I, págs. 73-76; el mismo paralelismo que se subraya en el Fisiólogo, ed. Marino Ayerra y Nilda Guglielmi, Buenos Aires, Eudeba, 1971, págs. 39-41, en el bestiario de Philippe de Thaon, trad. fragmentaria en Bestiario medieval, ed. Ignacio Malaxecherría, Madrid, Siruela, 1986, págs. 23-28, y en el Bestiaire Divin, de Guillaume de Normandie, ed. C. Hippeau, Ginebra, Slatkine Reprints, 1970, pág. 74. Para los bestiarios en general, y para el Fisiologo en particular, véase Florence MacCulloch, Mediaeval Latin and French Bestiories, Valencia, Chapel Hill, The University of Carolina Press, 1960. En las fábulas el león aparece como rey de los animales: «avía un león que era rey de todas las alimanias (...)* (Calila e Dimna, ed. Juan Manuel Cacho Blecua y Marf́a Jesús Lacarra, Madrid, Castalia, 1988, pág. 124). Jacques Ribard alude al valor del león en Le Moyen Age. Littérature et symbolisme, Paris, Champion, 1984, cap. «La symbolique des animaux et des plantes», págs. 61-62. 
Fuera cual fuere su significación, es evidente que ambos motivos contaron con una larga tradición en la Edad Media, incorporados a las infancias de la literatura artúrica y de la épica francesa, como dan cuenta Elyezer, el cual, según el Lancelot en prose, fue expuesto a una pareja de leones hambrientos como prueba de legitimidad cuando aún no contaba con tres dias ${ }^{34}$; Renier, que fue servido como pasto a unos leones, los cuales, a pesar de que en dos días no habían recibido alimento, se tumbaron a su alrededor, por lo que fue considerado hijo de rey ${ }^{35}$, y Lion de Bourges, que fue amamantado por una leona después de que quedara solo en un bosque ${ }^{36}$; en los tres casos los niños habían nacido con una marca de nacimiento de forma similar a Esplandián ${ }^{37}$. Siendo pequeño, una leona se

33 Alfred Maury, Croyances et légendes du Moyen Age, París, Champion, 1896, «le lion», págs. 240-248: «le lion est l'emblème de la force, de la puissance de cette vertu appelée "fortitudo divina", et qui fut celle des martyrs par excellence (...)»; «l'emblème de la forme morale de l'ermite, du démon vaincu et soumis» (págs. 241 y 246, respectivamente).

34 Lancelot en prose, VIII, LIIIa, 7, ed. A. Micha, Ginebra, Droz, 1980, tomo V, pág. 86; trad. Carlos Alvar, Lanzarote del Lago, Madrid, Alianza, 1988, vol. VI, págs. 1562-1563. Miguel Garci-Gómez, art. cit., alude a numerosos casos en que el león se amansa ante la santidad, la virginidad, la inocencia o la nobleza; incluye, además -en pág. 272 - el fragmento de una obra de amplia difusión - Sir Beues of Hamtoun - en que dos leones no hieren a Josián por ser hija de rey y virgen, vv. 2.388-2.394, pág. 115 de la ed. Eugen Kölbing, The Romance of sir Beues of Hamtoun, Londres, Early English Text Society, 1885-1894, vol. I, pág. 115; véase para el tema «Zu Shakespeare's King Henry IV», Englisch Studien, XVI, 1892, págs. 454-459, del mismo autor, donde alude a diversas obras en las que aparece el motivo. La razón no es la misma en Beufves de Hantonne; según la prosificación del cantar de gesta, los leones habrían matado a Josienne de no ser porque ésta se había encomendado piadosamente a Dios, ed. de Marie-Madeleine Ival, Senefiance, 15, Aix-en-Provence, Cuerma, 1984, pág. 73. A la inversa, el león reconoce y denuncia a la persona adúltera; Frederich Tubach, Index Exemplorum. A Handbook of Medieval Religious Tales, Helsinki, Suomalainen Tiedeakatemia, 1969, que no sigue el de S. Thompson aunque señala las correspondencias con el de Aarne's y tiene en cuenta diversas obras medievales castellanas; recoge con el núm. 59 de su índice el que designa como «Adulteres attacked by Lion», y puntualiza: «A lion always recognizes and attacks adulteresw, remite a diversas obras, entre las que figura la de Jacobo de Vitry. En el Lai d'Havelok, Argentille se casa con Havelok ignorando que es hijo de rey. Sin embargo, Argentille tiene una visión en que, entre otras cosas singulares, contempla cómo ambos suben a un árbol, asustados por la llegada de dos leones, que, en lugar de atacarlos, se someten a Havelok y le llaman señor. Al día siguiente, un ermitaño interpreta el sentido de la visión: Havelok debe ser de linaje real; él será rey, y ella reina (The Lay of Havelok, ed. Walter W. Skeat, Oxford, Clarendon Press, 1973; reimpr. de la 2:" ed., 1915).

ss Enfances Renier, ed. Carla Cremonesi, Milán-Varese, 1957, vv. 1.236-1.243, página 107.

36 Lion de Bourges. Poème épique du XIV• siècle, ed. cit., vv. 441-448, pág. 16.

37 Para la marca de nacimiento en general, véase el estudio de Karl Jaberg, «The Birthmark in Folk Belief, Language, Literature, and Fashion», Romance Philology, X, 19561957, págs, 307-342; François Delpech, «Les marques de naissance: physiognomonie, signature magique et charisme souverain», en Le corps dans la société espagnole des XVI ${ }^{*}$ et XVII siècles, A. Redondo ed., París, Presses de la Sorbonne, 1990, págs. 27-49, y «Du héros marqué au signe du prophète: esquisse pour l'archéologie d'un motif chevaleresque», 
llevó a uno de los hijos del caballero Zifar; las señales de la exposición -las cicatrices que habían dejado en la espalda del niño las dentelladas de la leona- no se habrían de borrar nunca ${ }^{38}$.

En síntesis, primero, Nasciano es introducido de forma indirecta en el relato a través de la alusión a su santidad y al carácter divino de su alimenmentación; después, su imagen a lomos de un asno y reverenciado por las bestias muestra una profunda humildad, a la vez que pone de manifiesto el poder extraordinario que ostenta sobre la naturaleza, y, más adelante, el amor hacia las crías de la leona evoca el recuerdo de la actitud franciscana frente a los animales. Su figura domina el pasaje desde la primera mención; pero desde que aparece al alba, íntimamente unido a Dios, hasta que ordena a la leona que amamante a Esplandián y ésta le obedece sumisamente, su personalidad inunda majestuosamente el relato al tiempo que lo sumerge en una atmósfera de una religiosidad absoluta y maravillosa, donde milagro y misterio devienen realidades cotidianas.

El interés de Nasciano está supeditado a la influencia que ejerce sobre Esplandián; si el espacio que lo rodea, su personalidad y su relación con el entorno están tan cuidadosamente descritos, no es por el ermitaño en sí mismo, sino porque Esplandián será su producto, porque su modo de ser posterior será la expresión de todas esas circunstancias que rodearon su crianza y educación, y es por ello por lo que el ambiente maravilloso-cristiano de la floresta adquiere plena significación. Ahora bien, desde el primer momento el papel de ese espacio no se limita a servir de escenario a la infancia de Esplandián que se une intimamente al personaje, inicialmente por su relación con Nasciano, pero también por algo mucho más poderoso como es su ligazón con la leona a partir de su amamantamiento. La exposición a la fiera es un

Bulletin Hispanique, XCII, 1990, págs. 237-257, y mi comunicación «El nacimiento de Esplandián y el folclore», III Congreso de la Asociación Hispánica de Literatura Medieval, Salamanca, 1989, para la marca de Esplandián; así como Ferdinand Lot, «La croix des royaux de France», Romania, XX, 1891, págs. 278-281, y Léon Gautier, Les épopées françaises, ed. cit., vol. II, pág. 497, para la tradición de la «croix royale». March Bloch tituló «Les supertitions; le signe royal; les rois et les lions» a uno de los apartados de sus Rois Thaumaturges, París, Gallimard, 1983, págs. 245-258, donde incluye una lista de personajes nacidos con la «croix royal». Para March Bloch, la creencia en que los reyes nacían con una señal de identidad prueba que eran tenidos por seres maravillosos, sagrados, una suerte de santos, como evidencia también la superstición de que los leones respetaban a los reyes; tales marcas son exponentes de una tradición universal, arraigada entre los griegos, para quienes los miembros de las dinastías gobernantes nacían con diferentes señales en su piel: una lanza para los nobles tebanos; un ancla para los Seléucidas. Su valor es el mismo cualquiera que sea su forma «autant qu'une marque d'origine, elle est un signe de prédestination; elle annonce un sort royal, qui, du reste, trouve sa justification ordinaire dans les privilèges du sang» (pág. 254). Téngase en cuenta también el art. de Antoine Thomas, "Le "signe royal" et le secret de Jeanne d'Arc», Revue Historique, CIII, 1910, págs. 278-282.

38 Libro del Caballero Zifar, ed. J. González Muela, Madrid, Castalia, 1982, pág. 114. 
elemento de carácter iniciático ancestral, que prueba la condición real del sujeto, además, a través del amamantamiento, el animal transfiere sus cualidades al niño: resulta significativo por tanto que el león a la vez que símbolo de poderío y realeza, sea la imagen de Jesucristo y de la santidad en general.

Al incorporar todos estos elementos, el relato que abre la vida de Esplandián se acomoda perfectamente a su carácter adulto; $y$, aunque parece en determinados momentos una narración extraída de un libro hagiográfico, tal ambientación, fuertemente cristianizada, ya pertenecía al "roman" artúrico en prosa, a la que el Amadis recurre para crear un personaje más acorde con su espíritu, cuya naturaleza cobrará sentido en el fin religioso que Esplandián dará a sus hazañas en las Sergas. Por todo ello, el pasaje comparte elementos tanto propios de la hagiografía como de la literatura heroica; en todo caso, elementos que habían pasado a formar parte del universo artúrico, que el autor de Amadis recoge e intensifica hasta el extremo, para configurar el personaje de Esplandián y dotar a su obra de un nuevo sentido caballeresco, heroico y cristiano a la vez. 